\title{
Serum prolactin in coeliac disease: a marker for disease activity
}

\author{
Ram Reifen, Dan Buskila, Moshe Maislos, Joseph Press, Aaron Lerner
}

\begin{abstract}
Prolactin, a polypeptide hormone of anterior pituitary origin, has pronounced physiological effects on growth, reproduction, and osmoregulation. Increasing evidence indicates that prolactin also has an immunomodulatory influence on the immune system. The status of prolactin in patients with coeliac disease was investigated by obtaining serum samples from 48 patients with active and non-active coeliac disease. These were compared with samples from 20 children with familial Mediterranean fever and 65 normal controls. Serum prolactin in patients with active coeliac disease was significantly higher than in the other groups studied and reference values. Serum prolactin correlated well with the degree of mucosal atrophy and with the serum concentration of antiendomysial antibodies. Prolactin may play a part in immune modulation in the intestinal damage of coeliac disease and serve as a potential marker for disease activity.

(Arch Dis Child 1997;77:155-157)
\end{abstract}

Keywords: coeliac disease; prolactin

Coeliac disease is a disorder in which the immune response to ingested gluten, a water soluble storage protein of wheat, is accompanied by intestinal mucosal damage. The resulting atrophy of the villi of the proximal small intestine leads to the malabsorption of nutrients and diarrhoea. Symptoms and epithelial damage can be resolved by excluding gluten from the diet. Although a variety of pathogenic mechanisms has been suggested, most evidence suggests that the tissue damage occurs as a consequence of the immune response. ${ }^{1}$ The involvement of both humoral and cellular immune pathways in coeliac disease indicates that the immune system plays a major part in the development of the disease. Evidence for humoral immune activation in coeliac disease is obtained from the increased production of antigliadin, antireticulin, and antiendomysial antibodies in active coeliac disease. ${ }^{2}$ The involvement of cellular immunity is implied by several findings such as an increase in the number of mitogen primed memory cytotoxic T cells $\left(\mathrm{CD} 45 \mathrm{RO}^{+}\right)$in the atrophied intestine and in the percentage of T cells expressing $\gamma \delta \mathrm{T}$ cell receptor subsets in the damaged mucosa. ${ }^{3}$ Coeliac disease exhibits many of the characteristics of an autoimmune disease, including polygenic inheritance, human leucocyte anti- gen linkage, target organ lymphocyte infiltration, restricted use of the $\mathrm{T}$ cell receptor, and its association with other autoimmune disorders. ${ }^{34}$ Coeliac disease may therefore be regarded as a disorder initiated in genetically predisposed subjects by an undefined trigger, in which the immune response, induced by ingested gluten, leads to organ specific tissue damage.

Prolactin has been implicated as an important in vivo modulator of cellular and humoral immunity. Experimental evidence suggests that sex linked hormonal factors influence the immune response and modify the expression of autoimmunity in animals and humans. ${ }^{5}$ Prolactin is a polypeptide hormone of anterior pituitary origin which has pronounced physiological effects on growth, reproduction, and osmoregulation in a wide range of species. ${ }^{7}$ As both coeliac disease and prolactin affect humoral immunity, cell mediated immunity, and autoimmunity, ${ }^{28}$ we evaluated serum prolactin in patients with active and treated coeliac disease with respect to the severity and activity of the disease.

\section{Patients and methods}

Forty eight patients with coeliac disease who fulfilled the diagnostic criteria of the European Society of Paediatric Gastroenterology and Nutrition ${ }^{9}$ were divided into two groups. The first group comprised 26 children with active coeliac disease (mean age 11.3, range 5-18 years, ratio of girls to boys $1: 1$ ) receiving a diet containing gluten. The second group comprised 22 children with coeliac disease (mean age 9.0 , range $4-15$ years, ratio of girls to boys $1.2: 1)$ in remission who had been receiving a gluten free diet for at least one year.

The patients with coeliac disease were compared with two other groups of 85 children. One comprised 65 normal schoolchildren who were seen at an outpatient clinic for routine check ups (mean age 11.5, range 5-18 years, ratio of girls to boys $1: 1$ ). The other group included 20 children with familial Mediterranean fever (an inflammatory disease) seen at a paediatric rheumatology immunology clinic (mean age 6.8, range 5-18 years, ratio of girls to boys $1: 1$ ). Informed consent was obtained from the parents and the study was approved by the hospital's institutional review board.

All patients with coeliac disease underwent upper gastrointestinal endoscopy with a GIFXQ-10 endoscope (Olympus, Japan). A small intestinal biopsy sample was taken from the third part of the duodenum and routinely 
processed for histological examination. The specimens were graded I-IV according to the degree of intestinal atrophy, as described previously. ${ }^{10}$

The basal concentration of prolactin was determined in all patients and defined as the prolactin concentration in the serum or plasma without stimulation. ${ }^{11}$ All blood samples were obtained in the mid-morning. Serum samples were collected and frozen at $-70^{\circ} \mathrm{C}$ until analysis. The serum prolactin level was measured by immunoradiometric assay (Promed, Holland) ${ }^{12}$ Normal concentrations of prolactin ranged from 5 to $20 \mu \mathrm{g} / 1$ and hyperprolactinaemia was defined at $>20 \mu \mathrm{g} / \mathrm{l}$. The intra-assay coefficient of variance was $3 \%$ and the interassay coefficient of variance was $5 \%$. None of the subjects with hyperprolactinaemia had been treated with drugs known to raise prolactin levels (such as chlorpromazine, metoclopramide). The results of thyroid, liver, and kidney function tests were normal in all patients.

Tests for the $\operatorname{IgA}$ antiendomysial antibody were performed by an indirect immunofluorescence assay as described previously. ${ }^{13}$ Serum samples were screened at serial dilutions and, if positive, the highest dilution yielding a positive reaction was reported.

The means were compared by one way analysis of variance.

\section{Results}

Mean serum prolactin concentrations were lowest in children with familial Mediterranean fever, those with inactive coeliac disease, and in the healthy children (fig 1), and highest in patients with active coeliac disease $(p<0.01)$. Prolactin concentrations were higher than normal $(>20 \mu \mathrm{g} / \mathrm{l})$ in seven of the patients with active coeliac disease. In the patients with coeliac disease on a gluten free diet, small intestinal biopsy specimens were histologically normal, whereas six patients with coeliac disease on a diet containing gluten had grade II atrophy, three had grade III atrophy, and 10 had total atrophy (grade IV). Antiendomysial antibodies were detected in all children with active coeliac disease. The antibody titre was widely distributed, ranging between 1:5 and 1:160. A close correlation was found between the grade of mucosal atrophy and the prolactin concentration: the higher the grade of mucosal atrophy, the higher the measured prolactin $(\mathrm{p}<0.004, r=0.98)$. A positive correlation was observed between the levels of antiendomysial antibodies and prolactin ( $\mathrm{p}<0.02, r=0.91)$. No correlation was detected between the prolactin level and the patients' age or sex.

\section{Discussion}

A link between the neuroendocrine and immunological systems has been established. ${ }^{14}$ Endocrine and autocrine mediators and receptors of the immune and endocrine systems may explain changes in immune function in response to environmental stimuli perceived by the central nervous system. ${ }^{15}$ Prolactin may play a part in the regulation of both humoral and cell mediated responses. ${ }^{15}$ Although both

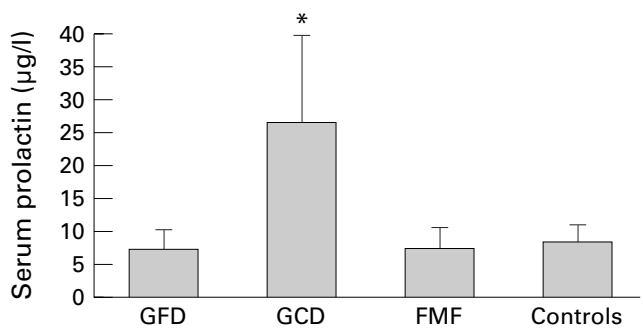

Figure 1 Mean (SD) serum prolactin concentrations $(\mu \mathrm{g} / \mathrm{l})$ in children with coeliac disease on a gluten free diet (GFD), children with coeliac disease on a gluten containing diet $(G C D)$, children with familial Mediterranean fever (FMF), and normal controls. Asterisk indicates higher than GFD, FMF, and control group $(p<0.01)$.

$\mathrm{T}$ and $\mathrm{B}$ lymphocytes contain prolactin binding sites, the growth promoting properties of prolactin are more evident in populations of $\mathrm{T}$ cells.

Prolactin participates in the immune regulation and stimulation of autoimmunity in human autoimmune disease. High serum prolactin concentrations were reported in male patients with systemic lupus erythematosus and in autoimmune thyroid disease..$^{15}$ No correlation has been found between the activity of the disease in patients with systemic lupus erythematosus and prolactin values, however. ${ }^{17}$ Furthermore, in an abstract describing increased prolactin concentrations in an untreated man with coeliac disease, ${ }^{18}$ a possible trophic effect of prolactin in patients with coeliac disease has been suggested.

In this study higher serum prolactin concentrations were found in patients with active coeliac disease on a diet containing gluten than in patients with coeliac disease on a gluten free diet. No difference in prolactin concentrations was found between the control group and patients with familial Mediterranean fever, suggesting that prolactin may play a part in the subgroup of patients with active coeliac disease. Familial Mediterranean fever was chosen as a control group because of its inflammatory nature, although we accept that a more appropriate control group might have been children with Crohn's disease.

The significant correlation between the effect of serum prolactin on the degree of intestinal damage and the activity of serum antiendomysial antibodies further substantiates the relevance of our observations. As intestinal pathology and levels of antiendomysial antibodies are reliable markers for coeliac disease, serum prolactin concentrations may serve as an additional marker of disease activity.

The higher prolactin serum concentrations in gluten induced enteropathy may play a primary part in the immune modulation of intestinal damage or may represent a secondary phenomenon.

1 Rosenberg R-WMC, Montzaris GZ, Jewell DP. The immunology of coeliac disease. In: Branski D, Rozen P, Kagnoff $\mathrm{MF}$, eds. Gluten sensitive enteropathy. Frontiers of gastrointestinal research. Vol 19. Basle: Karger, 1992: 29-43.

2 Lerner A, Kumar V, Iancu TC. Immunological diagnosis of childhood coeliac disease: comparison between antigliadin antireticulin and antiendomysial antibody. Clin Exp Immunol 1994;95:78-82. 
3 Lahat N, Ben Nun A, Kinarti E, Lerner A. T cell receptor repertoire in the peripheral blood and intestinal mucosa of repertoire in the peripheral blood and intestinal mucosa

4 Lerner A, Blank M. Shoenfeld Y. Coeliac disease and autoimmunity. Isr $\mathcal{F}$ Med Sci 1996;32:33-6.

5 Steinberg AD, Melez KA, Raveche ES, et al. Approach to the study of the role of sex hormones in autoimmunity. Arthritis Rheum 1979;22:1170-6.

6 Ansar AS, Penhale WJ, Talal N. Sex hormones, immune responses and autoimmune diseases: mechanisms of sex hormone action. Am f Pathol 1985;121:531-51.

7 Tyson JE, Pinto H. Identification of the possible significance of prolactin in human reproduction. Clin Obstet Gynecol 1978;5:411-34

8 Russel DH, Kibler R, Matrisian L, Larson DF, Poulos B, Magun BE. Prolactin receptors on human $T$ and $B$ lymphocytes: antagonism of prolactin binding by $\mathrm{cy}_{-}$ lymphocytes: antagonism of prolactin

9 Walker-Smith JA, Guandalini S, Schmitz J, et al. Revised criterion for the diagnosis of coeliac disease. Report of working group of European Society of Pediatric Gastroenworking group of European Society of Pediatric Gastroe
terology and Nutrition. Arch Dis Child 1990;65:909-11.

10 Lerner A, Gruener N, Iancu TC. Serum carnitine concentration in coeliac disease Gut 1993;34:933-5.

11 Vance ML, Thorner MO. Prolactin: hyperprolactinemic syndromes and management. In: De Groot LJ, ed. Endocrinology. 2nd Ed. Philadelphia: Saunders, 1989: 408
12 Baines MG, Rafferty B, Patel U, Fergusun K, Jeffcoate SL, Thorpe $\mathrm{R}$. The production and characterization of monoclonal antibodies against human prolactin and the development of a two site immunoradiometric assay. $\mathcal{F}$ Immunoassay 1989;10:75-91.

13 Rossi TM, Kumar V, Lerner A, Heitlinger LA, Tucker N, Fisher J. Relation of endomysial antibodies to jejunal mucosal pathology: specificity towards both symptomatic and asymptomatic coeliac. 7 Pediatr Gastroenterol Nutr 1988;7:858-63.

14 Lavalle C, Loyo E, Paniagua R. Correlation study between prolactin and androgens in male patients with systemic lupus erythematosus. F Rheumatol 1987;14:268-72.

15 Buskila D, Sukenik S, Shoenfeld Y. The possible role of prolactin in autoimmunity. Am 7 Reprod Immunol 1991;26: 118-23.

16 Pelkonen R, Salmi J, Lamberg BA. Interrelationship between TSH and prolactin secretion in patients with prolactinoma and autoimmune thyroiditis. Acta Endocrinol 1982;100:184-8.

17 Buskila D. No correlation between prolactin levels and clinical activity in patients with systemic lupus erythematosus. $\mathcal{F}$ Rheumatol 1996;23:629-32.

18 Muller E, Bates T, Samson D, Dowling R.H. Is prolactin trophic to the intestine? Gut 1977;18:A965. 